\title{
Psychological Impact: Unseen Effects of COVID-19
}

\author{
Johnson Alex, Gauri Nadkarni Choudhary ${ }^{1}$ \\ Associate Professor of Clinical Psychology, Department of Behavioral Sciences, College of Medicine, Dar Al Uloom University, Riyadh, Saudi Arabia, \\ ${ }^{1}$ Department of Clinical Psychology, Consultant Clinical Psychologist, Meadowlark Healthcare, Pune, India
}

\section{Abstract}

Impact of COVID-19 on mental health has affected various dimensions of human life. Various emergency government decisions and policies were developed during this period. Forced implementation of lockdown and quarantine during the pandemic made a significant impact on the general public and frontline health-care workers. The uncertainty due to COVID-19 caused major psychological problems such as anxiety, depression, stress, uncontrolled fear, and significant lifestyle changes. It has affected the world economy and also changed education and learning process.

Keywords: Anxiety, COVID-19, depression, posttraumatic stress disorder, psychological burden

\section{INTRODUCTION}

The World Health Organization (2020) declared the novel coronavirus COVID-19 as a global pandemic, and it has been a source of distress and uncertainty among people. The impact of COVID-19 has affected various dimensions of human life. Statistics reveal that in the beginning, the fatality rate was $1 \%-2.1 \%,{ }^{[1]}$ and later, the global case-fatality ratio increased up to $6.2 \%$. This created panic among people. The nature of psychological impact depends on several factors. Adjusting to "new normal" has been difficult and a source of stress. It has caused anxiety, posttraumatic stress disorder (PTSD), exaggerated hypervigilance, and depression. This crisis caused large-scale behavior changes in various areas of human life from elaborate cleaning behaviors to psychological burden. At the same time, some people have developed an "optimism bias." In the social context, people developed an intolerance and punitive attitude in the form of prejudice and discrimination. In addition to that, people were influenced by the specific norms, social inequality, and political polarization. ${ }^{[2]}$

\section{The Psychological Burden of COVID-19 \\ Quarantine and psychological distress}

Quarantine is defined as a strict period of isolation in order to avoid the spread of a disease. This isolation leads to complete loss of contact with loved ones and family members. The

\begin{tabular}{|l|l|}
\hline \multicolumn{3}{|c|}{ Access this article online } \\
\hline Quick Response Code: & Website: \\
\hline & www.ijrc.in \\
\hline & \\
\hline
\end{tabular}

psychological impact of isolation has been documented by several studies conducted worldwide. Most studies have indicated that there is a positive correlation between the duration of quarantine/lockdown and psychological distress among the general public. The fear and anxiety reactions in the general public have led the researchers to coin the term "corona phobia." Their results show the impact ranging from anxiety symptoms, fear, distress, frustration, disturbed sleep, and appetite which were seen as an immediate effect. ${ }^{[3]}$ The COVID-19 is a novel virus, and since not much information is available about its manifestation and prognosis, several studies report about stigmatization and isolation of the people who have tested positive. This has added to the psychological distress felt by these individuals. ${ }^{[4]}$ Due to the uncertainty about the spread of the virus, there has been an increase in obsessive-compulsive symptoms such as repeatedly checking temperature, excessive thoughts about contamination, and sanitizing and cleaning rituals. ${ }^{[5]}$ Studies have also reported a relationship between the duration of quarantine and the

Address for correspondence: Dr. Johnson Alex, Associate Professor of Clinical Psychology, Department of Medical Education, College of Medicine, Dar AI Uloom University, Riyadh, Saudi Arabia. E-mail: drjalex16@gmail.com

This is an open access journal, and articles are distributed under the terms of the Creative Commons Attribution-NonCommercial-ShareAlike 4.0 License, which allows others to remix, tweak, and build upon the work non-commercially, as long as appropriate credit is given and the new creations are licensed under the identical terms.

For reprints contact:WKHLRPMedknow_reprints@wolterskluwer.com

How to cite this article: Alex J, Choudhary GN. Psychological impact: Unseen effects of COVID-19. Indian J Respir Care 2021;10:S50-4.

Received: 23-12-2020 Revised: 02-02-2021

Accepted: 04-02-2021 Published: 29-04-2021 
severity of symptoms. Longer periods of quarantine have been associated with mental health problems such as PTSD. ${ }^{[6]} \mathrm{A}$ mass quarantine created a detachment from social support and community. This was an unusual experience to the individuals due to the stigma related to corona, burden due to loss of control, insufficient supply of basic essentials, separation from family members, financial loss, and increased perception of risk. The stigma associated with corona and quarantine led to discrimination, suspicion, avoidance by neighborhood, workplace prejudice, and withdrawal from social events. ${ }^{[3]}$

\section{Psychological distress among the general population}

The unexpected appearance of COVID-19 has caused a psychological burden among the general public. A study conducted on parents of hospitalized children during COVID-19 shows that depression and anxiety were high among parents admitted due to COVID-19 epidemic than patients admitted in the hospital due to nonepidemic reason. ${ }^{[7]}$ A case study report from India shows that self-harm and suicide have increased during this period. Increasing concern about the spread of COVID-19 has created panic among the public, and many people were suffering from subsyndromal depression. ${ }^{[8]}$

A web-based cross-sectional survey of 7236 volunteers reported a higher prevalence of depression and generalized anxiety disorder in younger age group than older age group. In addition to that, $35.1 \%$ of people were experiencing poor sleep quality. Their study identified a major mental health burden associated with COVID-19 in public group. ${ }^{[9]}$ Another online-based survey conducted in Saudi Arabia among the general population reported that one-fourth of the sample $(n=1160)$ were experiencing depression, anxiety, and stress and in general moderate-to-severe psychological impact due to COVID-19. ${ }^{[10]}$

A study conducted among student population on stress and anxiety during the COVID-19 pandemic in France reported that student population experienced moderate-to-severe stress during the lockdown and students who could not relocate were severely affected ${ }^{[11]}$ A similar study conducted in Bangladesh to explore the stress related to COVID-19 showed that $51 \%$ of people reported stress. Unemployment, wage reduction and other worries such as COVID-19 induced anxiety, depression, dysthymia and even suicide were identified. ${ }^{[12]}$

Ornell et al. reported that COVID-19 has created a significant psychological burden among the public in the form of intense emotional and behavioral reactions such as fear, boredom, anger, loneliness, anxiety, and insomnia.

Similarly, another study on psychological impact of COVID-19 on the general public documented the role of COVID-19 as a risk factor to develop a potential psychiatric disorder among vulnerable individuals. ${ }^{[13]}$ Many studies reported that various psychological problems faced by the general public were pervasive anxiety, frustration and boredom, disabling loneliness, poor resilience, specific and uncontrolled fears related to infection, and significant lifestyle changes.
A study conducted among 6509 individuals in Germany reported that $50 \%$ of the sample had anxiety and psychological distress in relation to COVID-19. The risk perception of the general population was high; the fear of becoming infected was very prevalent in this study. Similarly, hours spent thinking about COVID-19 was significant among general population, more so in women who spent more time thinking about COVID-19 than men. ${ }^{[14]}$

Sixty-five percent of the sample reported anxiety and depressive symptoms in a Spanish study among the general population. The study focusing on coping behaviors to decrease anxiety and depression suggested that healthy/balanced diet and not reading news/updates about COVID-19 were the best coping strategies to lower the anxiety symptoms. ${ }^{[15]}$

Several studies conducted on online platforms have documented that the general public has reported an increase in negative emotions such as anxiety or depression and a decrease in positive emotions such as happiness and life satisfaction. ${ }^{[16]}$ Few other studies have reported that women, people of younger age, students, and people with comorbid conditions experienced more distress. ${ }^{[17]}$ Other studies have reported psychological distress among those who have lost a loved one to the pandemic due to inability to have adequate closure. ${ }^{[18]}$

Several studies have documented the impact of the pandemic on individuals with preexisting psychiatric conditions. Unavailability of prescription drugs, difficulty in meeting the health-care professionals, etc., have led to increase in the distress levels reported by these individuals. ${ }^{[19]}$ Studies also report a considerable increase in symptoms of people on the anxiety spectrum. A multicentric study titled ECLB-COVID-19 found a significant impact of lockdown and social distancing on mental health and well-being. ${ }^{[6]}$ The risk factors highlighted by their study included physical and social inactivity, unhealthy lifestyles, and sleep patterns.

A study conducted on the Chinese students identified higher age, living in confined areas with a higher number of infected cases, insecure attachment patterns, and lower levels of coping as risk factors for developing symptoms of anxiety, depression, and PTSD. ${ }^{[20]}$ An Italian study found that females, those who spent a significant time on the Internet, and those who avoided routine activities were at risk for developing symptoms of psychological distress. ${ }^{[21]}$ Similarly, a Cyprus-based study concluded that the risk factors included the feminine gender, student population, having loved ones stuck abroad, past history of psychiatric or medical illness, and having a poor quality of life. ${ }^{[19]}$

Suicide rate has increased steadily in India during the COVID-19 pandemic period. Suicide rate was high among the age between 18 and 35 years (52.94\%) among the reported victims of suicide. Further analysis shows that a number of cases were more among male $(82.35 \%)$ than female population. The major reasons for suicide were fear of infection, depression, loneliness, perceived stigma, and misinterpretation of fever as COVID-19. ${ }^{[22]}$ 


\section{Psychological distress among frontline workers}

Frontline health-care workers suffered from various psychological problems. Anxiety, acute stress, and other psychiatric symptoms were reported from frontline health-care workers. ${ }^{[23]}$ PTSD was very common among many health-care workers in the frontline of fight against COVID-19. Mild-to-extremely severe depression (13.6\%), anxiety (13.9\%), and stress $(8.6 \%)$ symptoms were present among 863 medical care workers of China. ${ }^{[24]}$

Health-care providers in intensive care unit were experiencing severe fatigue and burnout. The limited resources, longer shifts, disruption to sleep and work-life balance, and occupational hazards were the contributing factors to their burnout symptoms and other psychiatric symptoms. In addition to that, frontline health-care workers were unable to meet family members as part of preventing the spread of infection to the family members which intensified their worries about their family responsibilities. ${ }^{[25]}$

Another study reported from Italy conducted among frontline health-care providers states that as the whole nation was overloaded with COVID-19 patients, its health-care workforce was struggling to cope with challenges that could threaten their own well-being. The study indicated that Italian health-care professionals experienced work-related psychological pressure, emotional burnout, and somatic symptoms. ${ }^{[26]}$

Occupation stress was high among health-care workers during the COVID-19 pandemic. They experience high workload, strict organizational regulations, and insufficient time to cope with occupational challenges, a rapidly evolving knowledge base, and lack of interpersonal support in everyday life. It led to "emotional exhaustion" and diminished sense of self-efficacy and competence. ${ }^{[27]}$ Physician trainees who were at the forefront of care during the COVID-19 pandemic were experiencing stress and burnout.

\section{Changes in health-related behavior}

The imposed lockdown has brought a significant change in the lifestyle of individuals. There have been reported changes in eating patterns, sleep-wake cycles, and physical fitness routines. This has had a major impact on health-related behavior. Several studies have indicated a rise in obesity and related problems. A Spanish study conducted during the lockdown period showed men and obese people to be at a greater risk for weight fluctuations (loss and gain). There has also been a significant rise in unhealthy eating patterns, stress-related eating. Moreover, the study found a link between the presence of depressive symptoms and weight gain. ${ }^{[28]}$

A study in China reported the impact of psychological distress due to COVID on pregnant women and neonatal care. The lockdown, social isolation, and fear of contracting the illness have led to an increase in the anxiety and stress reaction of expectant mothers, impacting the health of both mother and neonate. ${ }^{[17]}$
The ECL-COVID ${ }^{[6]}$ online survey indicated significant changes in eating behavior and physical activity related to psychological distress. People were seen as eating poorer, eating junk, and stress eating. There was also a significant reduction in physical activity leading to poorer health and increased stress.

\section{Behavior changes and economic recession}

The COVID-19 has brought the world to a standstill. In order to combat the virus, most countries have imposed a lockdown. The lockdown, as well as the increasing medical expenditure, has pushed most of the world into recession. Several studies have explored the impact of this economic recession on behavior and mental well-being of people. A study from Nepal, severely affected by the lockdown as it is chiefly a tourism-based country, reported an increase in stress and anxiety due to economic recession. People resorted to panic buying and hoarding because of shortage of goods putting further strain on the economy. ${ }^{[29]}$

\section{Impact on educational learning}

The pandemic has led to closure of educational institutes for a prolonged period of time. Studies have indicated both short- and long-term impact on children. Short-term impacts were related to increased behavioral problems such as stubborn behavior, temper tantrums, and Internet addiction. Long-term consequences included anxiety, childhood obesity, decreased academic interest, and unhealthy eating and sleeping patterns. ${ }^{[30]}$ Studies have also predicted increased educational lag between higher and lower social income groups due to accessibility of electronic gadgets needed for online learning. Studies have also reported an increase in number of cases of child abuse and school dropouts. ${ }^{[31]}$ In addition to the children, the parents too reported of additional burden of looking after the school-going children at home. A study conducted in the United States also indicated a decline in academic performance as a result of closing of schools. ${ }^{[32]}$

\section{Behavior changes in children}

The combined effect of uncertainty of COVID, quarantine, and the lockdown has disrupted the lives of young children as well. With educational institutes, parks, play areas as well as other sources of entertainment shutting down, the children find themselves in completely unfamiliar situations. The early years of life are formative for cognitive, emotional, and physical development of children. Studies conducted to see the impact of COVID have found that both younger and older children are affected by stress due to decreased social interaction, family financial crisis, and cramped living conditions. This study also found that those children of single parents, health-care workers, and those whose parents needed to be quarantined were at a greater risk for developing adjustment problems. ${ }^{[33]}$

Other factors causing behavioral problems included confinement at home, lack of structured routine, and fear of infection. Several studies have pointed out the risk of development of symptoms of PTSD, anxiety, and phobic reaction due to the excess of information available on social media. ${ }^{[32]}$ Surveys conducted across the globe have reported an 
increase in domestic violence and sexual and physical abuse of children who are forced to live in close contact with their abusers. A study in Pakistan elaborated the potential short- and long-term risks on the physical and mental health of children, especially in early childhood. ${ }^{[34]}$ In developing countries, the economic recession and strain on health-care facilities can cause both maternal and children's health to be neglected. Lack of academic exposure, reduced interaction with peers, and lack of exposure can have an impact on their cognitive development. Moreover, living in confined space, economic difficulties, and fear of virus can cause symptoms of anxiety and fear, especially among young children. ${ }^{[35]}$

\section{Geriatric mental health}

The elderly are seen as "at-risk" population for contracting the virus due to old age as well as the presence of comorbid conditions. The pandemic has caused an increase in fear among the elderly as pointed out by several studies. Studies have concluded that the elderly with cognitive decline are more likely to get anxious, get agitated, and withdrawn. ${ }^{[3]}$

\section{Conclusion}

The research related to the COVID-19 pandemic has brought forth to light the importance of mental health care. The world in general has proved to be inept in dealing with mental health crisis. This mental health pandemic has affected people across age, gender, and economic background. The way forward is to ensure better mental health-care awareness and facilities to deal with the short- and long-term impact of this pandemic scare.

\section{Financial support and sponsorship}

Nil.

\section{Conflicts of interest}

There are no conflicts of interest.

\section{References}

1. Ioannidis J. The infection fatality rate of COVID-19 inferred from seroprevalence data. MedRxiv 2020:1-37.

2. Bavel JJ, Baicker K, Boggio PS, Capraro V, Cichocka A, Cikara M, et al. Using social and behavioural science to support COVID-19 pandemic response. Nat Hum Behav 2020;4:460-71.

3. Dubey S, Biswas P, Ghosh R, Chatterjee S, Dubey MJ, Chatterjee S, et al. Psychosocial impact of COVID-19. Diabetes Metab Syndr Clin Res Rev 2020;14:779-88.

4. Ammar A, Chtourou H, Boukhris O, Trabelsi K, Masmoudi L, Brach M, et al. COVID-19 home confinement negatively impacts social participation and life satisfaction: A worldwide multicenter study. Int J Environ Res Public Health 2020;17:1-7.

5. Zhang WR, Wang K, Yin L, Zhao WF, Xue Q, Peng M, et al. Mental health and psychosocial problems of medical health workers during the COVID-19 epidemic in China. Psychother Psychosom 2020;89:242-50.

6. Ammar A, Trabelsi K, Brach M, Chtourou H, Mueller N, Aloui A, et al. Title: Effects of home confinement on mental health and lifestyle behaviours during the COVID-19 outbreak: Insight from the "ECLB-COVID19" multi countries survey. medRxiv 2020. [doi: 10.1101/2020.05.04.20091017].

7. Yuan R, Xu QH, Xia CC, Lou CY, Xie Z, Ge QM, et al. Psychological status of parents of hospitalized children during the COVID-19 epidemic in China. Psychiatry Res 2020;288:112953.

8. Sahoo S, Rani S, Parveen S, Pal Singh A, Mehra A, Chakrabarti S, et al.
Self-harm and COVID-19 Pandemic: An emerging concern - A report of 2 cases from India. Asian J Psychiatr 2020;51:102104.

9. Huang Y, Zhao N. Generalized anxiety disorder, depressive symptoms and sleep quality during COVID-19 outbreak in China: A web-based cross-sectional survey. Psychiatry Res 2020;288:112954.

10. Alkhamees AA, Alrashed SA, Alzunaydi AA, Almohimeed AS, Aljohani MS. The psychological impact of COVID-19 pandemic on the general population of Saudi Arabia. Compr Psychiatry 2020;102:152192.

11. Husky MM, Kovess-Masfety V, Swendsen JD. Stress and anxiety among university students in France during Covid-19 mandatory confinement. Compr Psychiatry 2020;102:152191.

12. Islam SM, Bodrud-Doza M, Khan RM, Haque MA, Mamun MA. Exploring COVID-19 stress and its factors in Bangladesh: A perception-based study. Heliyon 2020;6:1-10.

13. Serafini G, Parmigiani B, Amerio A, Aguglia A, Sher L, Amore M. The psychological impact of COVID-19 on the mental health in the general population. QJM 2020;113:229-35.

14. Petzold MB, Bendau A, Plag J, Pyrkosch L, Mascarell Maricic L, Betzler F, et al. Risk, resilience, psychological distress, and anxiety at the beginning of the COVID-19 pandemic in Germany. Brain Behav 2020;10:1-10.

15. Fullana MA, Hidalgo-Mazzei D, Vieta E, Radua J. Coping behaviors associated with decreased anxiety and depressive symptoms during the COVID-19 pandemic and lockdown. J Affect Disord 2020;275:80-1.

16. Forte G, Favieri F, Tambelli R, Casagrande M. The enemy which sealed the world: Effects of COVID-19 diffusion on the psychological state of the Italian population. J Clin Med 2020;9:1802.

17. Nabi G, Siddique R, Xiaoyan W, Ullah R, Nawsherwan Xue M, Khan S, et al. COVID-19 induced psychosocial stressors during gestation: Possible maternal and neonatal consequences. Curr Med Res Opin 2020;36:1633-4.

18. Ho CS, Chee CY, Ho RC. Mental health strategies to combat the psychological impact of COVID-19 beyond paranoia and panic. Ann Acad Med Singap 2020;49:1-3.

19. Solomou I, Constantinidou F. Prevalence and predictors of anxiety and depression symptoms during the COVID-19 pandemic and compliance with precautionary measures: Age and sex matter. Int J Environ Res Public Health 2020;17:1-9.

20. Kontoangelos K, Economou M, Papageorgiou C. Mental health effects of COVID-19 pandemia: A review of clinical and psychological traits. Psychiatry Investig 2020;17:491-505.

21. Gualano MR, Lo Moro G, Voglino G, Bert F, Siliquini R. Effects of Covid-19 lockdown on mental health and sleep disturbances in Italy. Int J Environ Res Public Health 2020;17:1-3.

22. Shoib S, Nagendrappa S, Grigo O, Rehman S, Ransing R. Factors associated with COVID-19 outbreak-related suicides in India. Asian J Psychiatr 2020;53:2018-20.

23. Heath C, Sommerfield A, von Ungern-Sternberg BS. Resilience strategies to manage psychological distress among healthcare workers during the COVID-19 pandemic: A narrative review. Anaesthesia 2020;75:1364-71.

24. Si MY, Su XY, Jiang Y, Wang WJ, Gu XF, Ma L, et al. Psychological impact of COVID-19 on medical care workers in China. Infect Dis Poverty 2020;9:1-3.

25. Sasangohar F, Jones SL, Masud FN, Vahidy FS, Kash BA. Provider burnout and fatigue during the COVID-19 pandemic: Lessons learned from a high-volume intensive care unit. Anesth Analg 2020;131:106-11.

26. Barello S, Palamenghi L, Graffigna G. Burnout and somatic symptoms among frontline healthcare professionals at the peak of the Italian COVID-19 pandemic. Psychiatry Res 2020;290:113129.

27. Sultana A, Sharma R, Hossain MM, Bhattacharya S, Purohit N. Burnout among healthcare providers during Covid-19: Challenges and evidencebased interventions. Indian J Med Ethics. Published online on July 4, 2020. DOI:10.20529/IJME.2020.73. Available from https://osf.io/ preprints/socarxiv/4hxga/. [Last accessed on 2020 Nov 15].

28. Fernandez-Rio J, Cecchini JA, Mendez-Gimenez A, Carriedo A Weight changes during the COVID-19 home confinement. Effects on psychosocial variables. Obes Res Clin Pract 2020;14:383-5.

29. Poudel K, Subedi P. Impact of COVID-19 pandemic on socioeconomic and mental health aspects in Nepal. Int J Soc Psychiatry 2020;66:748-55. 
Alex and Choudhary: The psychological burden of COVID-19

30. Hirokazu Y, Wuemli Alice J, Rebello BP, Benard D, Leckman James F, Stephen LJ, et al. Effects of the global coronavirus disease-2019 pandemic on early childhood development: Short-and long-term risks and mitigating program and policy actions. J Pediatr 2020;223:188-93.

31. Cardenas MC, Bustos SS, Chakraborty R. A 'parallel pandemic': The psychosocial burden of COVID-19 in children and adolescents. Acta Paediatr Int J Paediatr 2020;109:2187-8.

32. Son C, Hegde S, Smith A, Wang X, Sasangohar F. Effects of COVID-19 on college students' mental health in the United States: Interview survey study. J Med Internet Res 2020;22:1-4.

33. Ghosh R, Dubey MJ, Chatterjee S, Dubey S. Impact of COVID -19 on children: Special focus on the psychosocial aspect. Minerva Pediatr 2020;72:226-35.

34. Hashmi AM, Saleem HA. New horizons: COVID-19 and the burden of neuropsychiatric illness in Pakistan. Pak J Med Sci 2020;36:S95-8.

35. Singh AK, Misra A. Impact of COVID-19 and comorbidities on health and economics: Focus on developing countries and India. Diabetes Metab Syndr Clin Res Rev 2020;14:1625-30. 